\title{
STRATEGI EXPERIENTIAL MARKETING DAN KUALITAS PELAYANAN DALAM MENJELASKAN KEPUASAN DAN LOYALITAS NASABAH PADA BANK SYARIAH MANDIRI SEMARANG
}

\author{
EXPERIENTIAL MARKETING STRATEGY AND QUALITY OF SERVICE IN \\ EXPLAINING CUSTOMER SATISFACTION AND LOYALTY IN MANDIRI \\ SYARIAH BANK SEMARANG
}

\author{
Arif Afendi \\ Fakultas Ekonomi dan Bisnis Islam \\ Universitas Islam Negeri Walisongo Semarang, Indonesia \\ Jl. Walisongo No.3-5, Tambakaji, Kec. Ngaliyan, Kota Semarang, Jawa Tengah 50185 \\ arifafendi@walisongo.ac.id
}

\begin{abstract}
ABSTRAK
Tujuan dari penelitian ini adalah untuk menguji pengaruh experiental marketing dan kualitas pelayanan terhadap kepuasan dan loyalitas nasabah.. Jenis penelitian yang digunakan adalah penelitan kuantitatif dengan menggunakan metode pengolahan data berupa Structural Equation Model (SEM). Data dalam penelitian ini berupa data primer dengan 100 responden nasabah Bank Syariah Mandiri (BSM) Semarang. Hasil penelitian ini menunjukkan bahwa adanya pengaruh positif dan signifikan variabel experiental marketing dan kualitas pelayanan terhadap kepuasan nasabah. Pengaruh kepuasan nasabah terhadap loyalitas nasabah adalah positif dan signifikan. Pengaruh kualitas pelayanan terhadap loyalitas nasabah juga positif dan signifikan. Sedangkan variabel experiental marketing pengaruhnya positif namun tidak signifikan terhadap loyalitas nasabah.
\end{abstract}

Kata kunci : experiental marketing, kualitas pelayanan, loyalitas nasabah, kepuasan nasabah

\begin{abstract}
The purpose of this research is to test the effect of experiental marketing and service quality on customer satisfaction and customer loyalty. The type of research used is quantitative research using the Structural Equation Model (SEM) method. The data in this study was primary data with 100 respondents of mandiri syaria bank (BSM) Semarang. The results of this study show that there is a positive and significant effect of experiental marketing and servic quality on customer satisfaction. The effect of the service quality on customer loyalty is positive and significant. The effect of customer loyalty is positive and significant while the effect of experiental marketing to customer loyalty is positive but not significant.
\end{abstract}

Keywords: experiental marketing, service quality, customer loyalty, customer satisfaction

\section{PENDAHULUAN}

Dunia bisnis saat ini dihadapkan pada persaingan global. Persaingan global tersebut bisa dilihat dari berkembangnya teknologi informasi yang sangat cepat. Perkembangan teknologi informasi membuat siapa saja dengan mudah bisa mengakses banyak informasi tanpa batas. Demikian halnya

\section{Arif Afendi}

Strategi Experiential Marketing Dan Kualitas Pelayanan Dalam Menjelaskan Kepuasan Dan Loyalitas Nasabah Pada Bank Syariah Mandiri Semarang 


\section{SEGMEN Jurnal Manajemen dan Bisnis \\ Volume 17 No 1 Januari 2021 \\ p-ISSN: 0216-938X e-ISSN: 2684-8414}

dengan pelanggan, mereka bisa mendapatkan banyak informasi mengenai produk dengan mudah. Situasi persaingan yang ketat menyebabkan perusahaan sulit untuk meningkatkan jumlah pelanggan. Persaingan tersebut juga menyulitkan bagi perusahaan untuk merebut pangsa pasar pesaing. Dengan kondisi seperti itu, tugas para pemasar sangat berat karena perubahan-perubahan dapat terjadi setiap saat, baik perubahan pada diri pelanggan seperti selera, maupun aspekaspek psikologis, dan sosial. Namun pemasar pada umumnya menginginkan bahwa pelanggan yang diciptakannya dapat dipertahankan selamanya.

Kegiatan pemasaran terus mengalami perkembangan dan banyak mengalami perubahan, dari konsep pemasaran konvensional menuju konsep pemasaran modern. Perkembangan ini karena banyaknya persaingan-persaingan dalam inovasi menciptakan suatu produk begitu juga dengan cara penjualannya. Perkembangan yang cepat dunia industri di sektor jasa terutama industri perbankan menuntut perusahaan untuk melakukan perubahan yang berorientasi terhadap cara mereka mengeluarkan produk, mempertahankan produknya, menarik nasabah, dan menangani pesaing agar para nasabah merasa puas akan produk dan pelayanan yang ditawarkan. Hal terpenting yang perlu dilakukan dan diperhatikan oleh perusahaan adalah bagaimana perusahaan membuat pelanggan puas sehingga membuat mereka semakin loyal dengan perusahaan tersebut. Menurut Tjiptono (2006) menyatakan kesuksesan dalam persaingan akan dapat dipenuhi apabila perusahaan mampu menciptakan kepuasan dan mempertahankan pelanggan. Syarat yang harus dipenuhi oleh sebuah perusahaan agar dapat sukses dalam persaingan adalah berusaha mencapai tujuan untuk Menciptakan kepuasan pelanggan.

Dalam menghadapi persaingan tersebut loyalitas pelanggan menjadi hal yang sangat penting bagi perusahaan. Menurut Griffin (2005) pelanggan yang loyal akan melakukan pembelian ulang secara berkala, membeli produk lain yang ditawarkan produsen yang sama, dan merekomendasikan produk atau jasa tersebut kepada orang lain. Perusahaan tentu ingin mempertahankan pelanggannya dalam jangka panjang, bahkan jika mungkin untuk selamanya. Loyalitas pelanggan ini muncul karena adanya pengaruh dari kepuasan yang dirasakan pelanggan (Wijayanti, 2008). Kepuasan pelanggan adalah tingkat dimana persepsi kualitas sebuah produk sesuai dengan harapan pelanggan. Dalam usahanya untuk mendapatkan kepuasan pelanggan, perusahaan tentunya akan melakukan berbagai startegi, salah satunya adalah dengan memberikan kualitas pelayanan yang baik kepada pelanggan. Layanan dengan kualitas yang baik mampu memengaruhi kepuasan pelanggan (Aryani dan Febriana, 2010). Pemberian kualitas layanan dilakukan dengan memperhatikan dimensi-dimensi kualitas pelayanan yaitu reliability, responsiveness, assurance, empathy, dan tangibility (Parasuraman et al., 1985). Kualitas pelayanan yang baik juga dapat meningkatkan loyalitas pelanggan (Lee, Hsiao, dan Yang, 2010).

Ada berbagai macam cara serta strategi yang dilakukan oleh perusahaan dalam memasarkan barang atau jasa kepada konsumen. mulai dari pengiklanan, 


\section{SEGMEN Jurnal Manajemen dan Bisnis \\ Volume 17 No 1 Januari 2021 \\ p-ISSN: 0216-938X e-ISSN: 2684-8414}

melakukan inovasi-inovasi terhadap produk atau jasa, pemberian undian berhadiah, promosi, pemberian pelayanan yang baik, adanya kritik dan saran terhadap suatu produk atau jasa dan masih banyak lagi lainnya yang bisa menciptakan kesan yang menarik sehingga pelanggan merasa puas dan mampu membedakan suatu produk atau jasa dengan yang lainnya. Konsep pemasaran yang memberikan pengalaman unik kepada pelanggan dikenal dengan istilah experiential marketing. Dalam pendekatan ini, pemasar menciptakan produk atau jasa dengan menyentuh panca indra, hati, dan pikiran konsumen. Produk dapat menyentuh nilai emosional konsumen secara positif dapat menjadikan memorable experience antara perusahaan dan konsumen. Hal ini berpengaruh sangat baik bagi perusahaan karena konsumen yang puas biasanya menceritakan pengalamannya menggunakan produk atau jasa suatu perusahaan kepada orang lain (Putri \& Astuti, 2010).

Experiential marketing mencoba menggeser pendekatan pemasaran tradisional berupa marketing mix yang biasanya hanya bertumpu pada feature dan benefit. Pada experiential marketing, perusahaan tidak hanya berorientasi pada feature dan benefit tetapi juga mengutamakan emosi pelanggan dengan memberikan fasilitas-fasilitas yang bisa memberikan pengalaman bagi pelanggan sehingga tercapai memorable experience yang membuat pelanggan mengulang kembali pengalamannya dan bahkan mau mengeluarkan uang lebih untuk menikmati pengalaman baru menggunakan fasilitas lain yang ditawarkan perusahaan. Schmitt (1999) menjelaskan konsep experiential marketing dapat di analisis melalui dua pendekatan, yaitu strategic experiential modules (SEMs) dan experiential providers (ExPros), dimana strategic experiential modules (SEMs) merupakan jenis pengalaman yang dihadirkan di dalam experiential marketing yang meliputi panca indera (sense), perasaan (feel), pikiran (think), tindakan ( act) dan hubungan sosial (relate). Sedangkan experiential providers (ExPros) merupakan peralatan yang digunakan untuk mengantarkan SEMs yang meliputi komunikasi, Identitas Visual, Kehadiran Produk, Kerjasama, lingkungan (spatial environment), website, dan penjual (people).

Unsur perasaan, pikiran, tindakan dan hubungan sosial yang dijadikan pedoman membuat experiential marketing berbeda dengan konsep tradisional. Sense ditujukan terhadap rasa dengan tujuan untuk menciptakan pengalaman melalui panca indra, feel ditujukan terhadap perasaan dan emosi positif yang timbul; think ditujukan terhadap intelektual dengan tujuan menciptakan kesadaran (cognitive), pengalaman untuk memecahkan masalah yang mengikutsertakan konsumen di dalamnya, actditujukan mempengaruhi pengalaman jasmaniah, gaya hidup, dan interaksi; dan relate ditujukan terhadap hubungan sosial konsumen. Penciptaan pengalaman konsumen dengan menggunakan experiential marketing diharapkan dapat menciptakan loyalitas pelanggan. Tuntutan konsumen yang menginginkan pengalaman lebih ketika menggunakan suatu produk atau jasa juga harus dipertimbangkan oleh pemasar agar konsumen memiliki ikatan emosional dengan produk atau jasa tersebut dan akan sulit untuk berpindah ke produk lain. 


\section{SEGMEN Jurnal Manajemen dan Bisnis \\ Volume 17 No 1 Januari 2021 \\ p-ISSN: 0216-938X e-ISSN: 2684-8414}

Hasil penelitian yang dilakukan oleh Yuan \& Wu (2008), Lee, Hsiao \& Yang (2010) dan Rosanti, Srikandi \& Yuliyanto (2013) mengatakan bahwa experiential marketing memiliki pengaruh yang positif terhadap kepuasan pelanggan. Experiential marketing bisa mendorong kepuasan pelanggan melalui nilai-nilai emosional dan fungsional artinya semakin baik pengalaman yang didapat oleh pelanggan maka kepuasan yang dirasakan akan semakin meningkat. Menurut Obonyo (2011) mengatakan bahwa experiential marketing memiliki pengaruh yang positif terhadap loyalitas pelanggan. Experiential marketing bisa mendorong kepuasan pelanggan melalui nilai-nilai emosional dan fungsional sehingga mengakibatkan pelanggan akan menjadi loyal artinya semakin baik pengalaman yang didapat oleh pelanggan maka kepuasan yang dirasakan akan semakin meningkat sehingga pelanggan akan menjadi semakin loyal terhadap perusahaan.

Peneltian

Sureshchandar,

Chandrasekharan \& Anantharaman (2002) dan Aryani \& Febriana (2010) menyatakan bahwa kualitas pelayanan memiliki pengaruh yang positif terhadap kepuasan pelanggan. Kualitas pelayanan yang baik di dalam suatu perusahaan, akan menciptakan kepuasan bagi para pelangganya. Setelah pelanggan merasa puas dengan produk atau jasa yang diterimanya, pelanggan akan membandingkan pelayanan yang diberikan. Apabila pelanggan merasa benar-benar puas, mereka akan membeli ulang serta memberi rekomendasi kepada orang lain untuk membeli di tempat yang sama. Artinya semakin baik tingkat kualitas pelayanan yang diberikan kepada pelanggan maka tingkat kepuasaan akan semakin tinggi. Penelitian Starini (2013) menyatakan bahwa kualitas pelayanan berpengaruh secara positif terhadap loyalitas pelanggan. Kualitas pelayanan merupakan faktor utama yang mempengaruhi loyalitas pelanggan dikarenakan pelanggan yang terpuaskan nilai pribadinya dan mengalami suasana hati yang positif terhadap pelayanan akan memiliki loyalitas yang tinggi terhadap perusahaan tersebut. Pelanggan seringkali tidak loyal disebabkan oleh adanya pelayanan yang buruk atau kualitas pelayanan yang semakin menurun dari yang diharapkan pelanggan. Hasil penelitian Lee, Hsiao \& Yang (2010) mengatakan bahwa kepuasan pelanggan memiliki pengaruh yang positif terhadap loyalitas pelanggan artinya ketika seseorang pelanggan merasa senang dan puas terhadap produk serta pelayanan yang diberikan maka akan membuat mereka semakin loyal dan setia terhadap produk tersebut serta akan semakin susah untuk pindah dengan menggunakan produk lain yang sejenis. Berdasarkan latar belakang diatas maka tujuan dalam penelitian ini adalah untuk menguji apakah experiential marketing dan kualitas pelayanan berpengaruh terhadap kepuasan nasabah dan loyalitas nasabah serta apakah kepuasan nasabah berpengaruh terhadap loyalitas nasabah.

\section{EXPERIENTIAL MARKETING}

Menurut Schmitt (1999) berpendapat bahwa experiential marketing adalah suatu kemampuan dari suatu produk dalam menawarkan pengalaman emosi hingga menyentuh hati dan perasaan konsumen. Experiential marketing adalah suatu konsep pemasaran yang bertujuan membentuk pelanggan yang loyal dengan cara menyentuh emosi 


\section{SEGMEN Jurnal Manajemen dan Bisnis \\ Volume 17 No 1 Januari 2021 \\ p-ISSN: 0216-938X e-ISSN: 2684-8414}

pelanggan dengan menciptakan pengalamanpengalaman positif dan memberikan suatu feeling yang positif terhadap jasa dan produk mereka. Schmitt (1999) menjelaskan konsep experiential marketing dapat di analisis melalui 2 pendekatan, yaitu strategic experiential modules (SEMs) dan experiential providers (ExPros), dimana strategic experiential modules (SEMs) merupakan jenis pengalaman yang dihadirkan di dalam experiential marketing yang meliputi sense (panca indera), feel (perasaan), think (pikiran), act (tindakan), dan relate (hubungan sosial), Sedangkan experiential providers (expros) merupakan peralatan yang digunakan untuk mengantarkan sems yang meliputi communications (komunikasi), visual identity (identitas visual), product presence (kehadiran produk), co- branding (kerjasama), spatial environment (lingkungan), website, dan people (penjual).

\section{KUALITAS PELAYANAN}

Menurut Parasuraman et al. (1985) Kualitas pelayanan adalah suatu kemampuan untuk memenuhi kebutuhan internal dan eksternal pelanggan secara konsisten sesuai prosedur. Dalam hal ini penyedia jasa dituntut untuk berusaha mengerti apa yang diinginkan pelanggan, sehingga mempunyai harapan untuk mendapatkan kualitas pelayanan yang baik. Kualitas pelayanan memiliki beberapa dimensi di antaranya adalah :

1. Reliability $\rightarrow$ Reliability adalaha konsistensi kerja dan keandalan kerja untuk memberikan pelayanan.

2. Responsiveness $\rightarrow$ Responsiveness adalah kesediaan untuk membantu pelanggan dan kesiapan untuk menyediakan pelayanan.

3. Assurance $\rightarrow$ Assurance adalah pengetahuan dan keahlian serta kemampuan untuk menyampaikan pelayanan.

4. Empathy $\rightarrow$ Empathy adalah kepedulian dan perhatian kepada pelanggan.

5. Tangibility $\rightarrow$ Tangibility adalah fasilitas fisik, penampilan pekerja, peralatan yang digunakan untuk memberikan pelayanan, peralatan yang digunakan untuk menyampaikan pelayanan.

\section{KEPUASAN PELANGGAN}

$$
\text { Menurut Kotler }
$$

mendefinisikan Kepuasan adalah perasaan senang atau kecewa seseorang yang muncul setelah membandingkan kinerja (hasil) produk yang dipikirkan terhadap kinerja (atau hasil) yang diharapkan. Jika kinerja berada di bawah harapan maka pelanggan tidak puas. Jika kinerja memenuhi harapan maka pelanggan puas. Jika kinerja melebihi harapan maka pelanggan amat puas atau senang.

Menurut Kotler \& Armstrong (2012), nilai pelanggan adalah perbandingan pelanggan antara semua keuntungan dan semua biaya yang harus dikeluarkan untuk menerima penawaran yang diberikan. Jumlah biaya pelanggan adalah sekelompok biaya yang digunakan dalam menilai, mendapatkan dan menggunakan produk atau jasa. Karena kepuasan pelanggan sangat tergantung pada persepsi dan ekspektasi pelanggan, maka sebagai pemasok produk perlu mengetahui faktor-faktor yang mempengaruhinya.

Menurut Tjiptono (2006), kepuasan konsumen merupakan situasi yang ditunjukkan oleh konsumen ketika mereka menyadari bahwa kebutuhan dan keinginannya sesuai dengan yang diharapkan serta terpenuhi secara baik. Menurut

\section{Arif Afendi}

Strategi Experiential Marketing Dan Kualitas Pelayanan Dalam Menjelaskan Kepuasan Dan Loyalitas Nasabah Pada Bank Syariah Mandiri Semarang 


\section{SEGMEN Jurnal Manajemen dan Bisnis \\ Volume 17 No 1 Januari 2021 \\ p-ISSN: 0216-938X e-ISSN: 2684-8414}

Zeithaml (1998) terdapat empat faktor yang mempengaruhi persepsi dan ekspektasi pelanggan, diantaranya adalah :

1. Apa yang telah didengar pelanggan dari pelanggan lainnya (word of mouth communication). Dimana hal ini merupakan faktor potensial yang menentukan ekspektasi pelanggan tersebut. Sebagai contoh, seorang pelanggan memiliki perusahaan yang diharapkan dapat memberikan pelayanan dengan kualitas tinggi berdasarkan rekomendasi dari teman-teman atau tetangganya.

2. Ekspektasi pelanggan sangat bergantung dari karakteristik individu dimana kebutuhan pribadi (personnel needs).

3. Pengalaman masa lalu (past experience) dalam menggunakan pelayanan dapat juga mempengaruhi tingkat ekspetasi pelanggan.

4. Komunikasi dengan pihak eksternal (external communication) dari pemberi layanan memainkan peranan kunci dalam membentuk ekspektasi pelanggan. Berdasarkan External communication, perusahaan pemberi layanan dapat memberikan pesan-pesan secara langsung maupun tidak langsung kepada pelanggannya. Sebagai contoh dari pengaruh adanya external communication adalah harga dimana biaya pelayanan sangat berperan penting dalam membentuk ekspektasi pelanggan.

\section{LOYALITAS NASABAH}

Menurut Kotler (2005), loyalitas pelanggan adalah suatu pembelian ulang yang dilakukan oleh seorang pelanggan karena komitmen pada suatu merek atau perusahaan. Loyalitas secara harfiah diartikan sebagai kesetiaan, yaitu kesetiaan seseorang terhadap suatu objek. Sikap loyalitas pelanggan akan terbentuk karena adanya pengalaman pelanggan setelah merasa puas dengan produk yang telah digunakan baik itu melalui kesan kualitas, asosiasi atau nama yang terkenal. Menurut Zeithaml et al. (2006) ada beberapa hal yang berkaitan dengan loyalitas konsumen, diantaranya adalah sebagai berikut

1. Say positive things $\rightarrow$ berkaitan dengan memberikan informasi hal-hal yang positif tentang produk yang telah dikonsumsi.

2. Recommend friend $\rightarrow$ dengan cara merekomendasikan produk yang telah dikonsumsi kepada teman.

3. Continue purchasing $\rightarrow$ dengan melakukan pembelian secara terus menerus terhadap produk yang telah dikonsumsi.

\section{MENJAGA LOYALITAS PELANGGAN.}

Banyak Pelaku bisnis yang setuju bahwa mencapai loyalitas pelanggan adalah hal yang baik. Biasanya bagi perusahaan pelanggan yang loyal akan mampu menghasilkan dividen sepanjang perjalanan bisnis perusahaan tersebut. Oleh karenanya sudah merupakan kewajiban bagi perusahaaan untuk memperyahankan pelanggan yang sudah loyal. Menurut Griffin (2005) agar dapat mempertahankan pelanggannyatidak berbalik kepada pesaing ada beberapa cara yang dapat dilakukan perusahaan antara lain:

\section{Arif Afendi}

Strategi Experiential Marketing Dan Kualitas Pelayanan Dalam Menjelaskan Kepuasan Dan Loyalitas Nasabah Pada Bank Syariah Mandiri Semarang 


\section{SEGMEN Jurnal Manajemen dan Bisnis \\ Volume 17 No 1 Januari 2021 \\ p-ISSN: 0216-938X e-ISSN: 2684-8414}

1. Meriset Pelanggan terus menerus (Regulary Research Of Customer). Kegiatan ini bertujuan untuk mengetahui apa yang diinginkan dan dibutuhkan konsumen.

2. Membuat hambatan agar pelanggan tidak pindah (Make a barrier for customer in order physical barrier). Ada tiga macam hambatan yang dapat dilakukan perusahaan agar pelanggannya tidak pindah ke pesaing, yaitu:

a. Hambatan Fisik (Physical Barrier) yaitu dengan menyediakan pelayanan fisik yang dapat memberikan nilai tambah bagi karyawan.

b. Hambatan Psikologis (Physicologi Barrier) yaitu dengan memberikan insentif kepada karyawan yang memberikan pemikiran kepada konsumen untuk selalu bergantung pada produk perusahaan.

c. Hambatan Ekonomis (Economic Barrier) yaitu memberikan insentif bagi pelayanan yang menguntungkan secara ekonomis misalnya memberikan potongan harga.

3. Melatih dan memotivasi staff untuk loyal (Training and motived staff to loyal) mengikutsertakan mereka dalam proses tersebut dengan memberikan pelatihan, dukungan dan imbalan agar mereka mau melakukan hubungan dengan konsumen.

4. Pemasaran untuk loyalitas (Marketing For Loyalty), merupakan pemasaran yang memberikan nilai tambah bagi perusahaan dan produk di mata konsumen. Ada beberapa cara yang bisa dilakukan antara lain: a. Relationship Marketing $\rightarrow$ Pemasaran yang bertujuan untuk membangun hubungan baik dengan konsumen.

b. Frekuensi Marketing $\rightarrow$ Pemasaran yang bertujuan untuk membangun komunikasi dengan pelanggan.Perusahaan dengan berkala membuat peranyaanpertanyaan tentang produk yang digunakan pelanggan.

c. Membership Marketing $\rightarrow$ Mengorganisasikan pelanggan dalam kelompok keanggotaan atau klub yang dapa mendorong mereka melakukan pembelian ulang dan meningkatkan loyalitas mereka.

\section{PENGEMBANGAN HIPOTESIS}

Menurut Yuan \& Wu (2008), Lee, Hsiao \& Yang (2010) dan Rosanti, Srikandi \& Yuliyanto (2013) mengatakan bahwa experiential marketing memiliki pengaruh yang positif terhadap kepuasan pelanggan. Experiential marketing bisa mendorong kepuasan pelanggan melalui nilai-nilai emosional dan fungsional artinya semakin baik pengalaman yang didapat oleh pelanggan maka kepuasan yang dirasakan akan semakin meningkat.

H1 : experiential marketing berpengaruh secara positif terhadap kepuasan nasabah.

\section{Menurut}

Sureshchandar, Chandrasekharan \& Anantharaman (2002) dan Aryani \& Febriana (2010) menyatakan bahwa kualitas pelayanan memiliki pengaruh yang positif terhadap kepuasan pelanggan. Kualitas pelayanan yang baik di dalam suatu perusahaan, akan menciptakan kepuasan bagi para pelangganya. Setelah pelanggan merasa puas dengan produk atau jasa yang

\section{Arif Afendi}

Strategi Experiential Marketing Dan Kualitas Pelayanan Dalam Menjelaskan Kepuasan Dan Loyalitas Nasabah Pada Bank Syariah Mandiri Semarang 


\section{SEGMEN Jurnal Manajemen dan Bisnis \\ Volume 17 No 1 Januari 2021 \\ p-ISSN: 0216-938X e-ISSN: 2684-8414}

diterimanya, pelanggan akan membandingkan pelayanan yang diberikan. Apabila pelanggan merasa benar-benar puas, mereka akan membeli ulang serta memberi rekomendasi kepada orang lain untuk membeli di tempat yang sama. Artinya semakin baik tingkat kualitas pelayanan yang diberikan kepada pelanggan maka tingkat kepuasaan akan semakin tinggi.

H2 : Kualitas pelayanan berpengaruh secara positif terhadap kepuasan nasabah.

Menurut Lee, Hsiao \& Yang (2010) mengatakan bahwa kepuasan pelanggan memiliki pengaruh yang positif terhadap loyalitas pelanggan artinya ketika seseorang pelanggan merasa senang dan puas terhadap produk serta pelayanan yang diberikan maka akan membuat mereka semakin loyal dan setia terhadap produk tersebut serta akan semakin susah untuk pindah dengan menggunakan produk lain yang sejenis.

H3 : Kepuasan nasabah berpengaruh secara positif terhadap loyalitas nasabah.

Menurut Starini (2013) menyatakan bahwa kualitas pelayanan berpengaruh secara positif terhadap loyalitas pelanggan. Kualitas pelayanan merupakan faktor utama yang mempengaruhi loyalitas pelanggan dikarenakan pelanggan yang terpuaskan nilai pribadinya dan mengalami suasana hati yang positif terhadap pelayanan akan memiliki loyalitas yang tinggi terhadap perusahaan tersebut. Pelanggan seringkali tidak loyal disebabkan oleh adanya pelayanan yang buruk atau kualitas pelayanan yang semakin menurun dari yang diharapkan pelanggan.

H4 : Kualitas pelayanan berpengaruh secara positif terhadap loyalitas nasabah

Menurut Obonyo (2011) mengatakan bahwa experiential marketing memiliki pengaruh yang positif terhadap loyalitas pelanggan. Experiential marketing bisa mendorong kepuasan pelanggan melalui nilai-nilai emosional dan fungsional sehingga mengakibatkan pelanggan akan menjadi loyal artinya semakin baik pengalaman yang didapat oleh pelanggan maka kepuasan yang dirasakan akan semakin meningkat sehingga pelanggan akan menjadi semakin loyal terhadap perusahaan.

H5 : Experiential marketing berpengaruh secara positif terhadap loyalitas nasabah

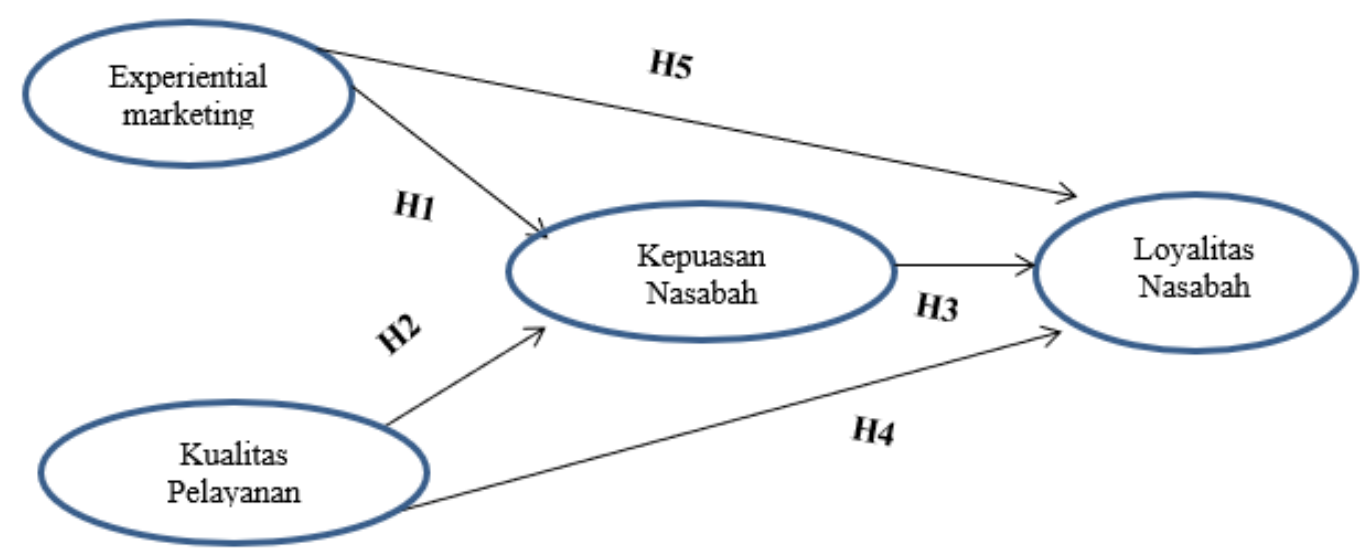

Gambar 1.

Model penelitian

Arif Afendi

Strategi Experiential Marketing Dan Kualitas Pelayanan Dalam Menjelaskan Kepuasan Dan Loyalitas Nasabah Pada Bank Syariah Mandiri Semarang 


\section{SEGMEN Jurnal Manajemen dan Bisnis \\ Volume 17 No 1 Januari 2021 \\ p-ISSN: 0216-938X e-ISSN: 2684-8414}

\section{METODOLOGI PENELITIAN}

\section{Data dan Sampel}

Jenis data yang digunakan dalam penelitian ini adalah data primer. Data diperoleh dari kuesioner dengan jumlah 100 responden. Sampel dalam penelitian ini adalah nasabah yang menabung di Bank Syariah Mandiri Semarang.

\section{Metode Analisis Data}

Analisis data yang digunakan dalam penelitian ini adalah data kuantitatif yang merupakan bentuk analisa dengan menggunakan angka-angka dan perhitungan dengan alat statistik. Penelitian membutuhkan suatu analisis data dan interpretasi yang akan digunakan untuk menjawab pertanyaan-pertanyaan dalam penelitian sehingga analisis data bisa lebih mudah dibaca dan diinterpretasikan. Pengujian hipotesa penelitian dilakukan dengan menggunakan teknik analisis Structural Equation Modelling (SEM) yang dioperasikan melalui program AMOS

\section{HASIL PENELITIAN DAN PEMBAHASAN \\ Deskripsi responden}

Data diambil menggunakan kuesioner yang dibagikan kepada nasabah Bank Syariah Mandiri Semarang. Sedaangkan teknik pengambilan sampel yang digunakan adalah Probability Sampling dan termasuk dalam teknik Simple Random Sampling.

\section{Responden menurut Jenis Kelamin}

Data Karakteristik responden berdasarkan jenis kelamin dapat dilihat pada tabel berikut :
Responden menurut Jenis Kelamin

\begin{tabular}{|c|c|c|}
\hline Keterangan & Jumlah & Persentase \\
\hline Pria & 46 & $46 \%$ \\
\hline Wanita & 54 & $54 \%$ \\
\hline Jumlah & 100 & $100 \%$ \\
\hline
\end{tabular}

Sumber : Data Primer yang Diolah, 2020

Berdasarkan tabel 1 menunjukkan bahwa jenis kelamin wanita paling dominan dengan jumlah 54 orang atau presentase sebesar 54\% sedangkan untuk pria sebanyak 46 orang atau $46 \%$ persen.

\section{Responden menurut Usia}

Data Karakteristik responden berdasarkan usia dapat dilihat pada tabel berikut:

Tabel 2

\begin{tabular}{|c|c|c|}
\multicolumn{1}{c}{ Responden Menurut Usia } \\
\hline Keterangan & Jumlah & Presentase \\
\hline $20-30$ & 15 & $15 \%$ \\
\hline $31-40$ & 35 & $35 \%$ \\
\hline$>41$ & 50 & $50 \%$ \\
\hline Jumlah & 100 & $100 \%$ \\
\hline
\end{tabular}

Sumber : Data Primer yang Diolah, 2020

Dari tabel 2 diatas menunjukkan bahwa responden dengan usia $>40$ Tahun paling dominan dengan jumlah 50 orang atau dengan prosentase $50 \%$. Sedangkan untuk usia 20 - 30 Tahun sebesar 15 orang atau $15 \%$ dan untuk usia 31-40 Tahun sebanyak 35 orang atau $35 \%$.

\section{Tabel 1}

Responden menurut Pendidikan Terakhir

Arif Afendi

Strategi Experiential Marketing Dan Kualitas Pelayanan Dalam Menjelaskan Kepuasan Dan Loyalitas Nasabah Pada Bank Syariah Mandiri Semarang 


\section{SEGMEN Jurnal Manajemen dan Bisnis \\ Volume 17 No 1 Januari 2021 \\ p-ISSN: 0216-938X e-ISSN: 2684-8414}

Data Karakteristik responden berdasarkan Pendidikan Terakhir dapat dilihat pada tabel berikut :

Tabel 3

\section{Responden menurut Pendidikan Terakhir}

\begin{tabular}{|c|c|c|}
\hline Keterangan & Jumlah & Presentase \\
\hline SMP & 18 & $18 \%$ \\
\hline SMA & 25 & $25 \%$ \\
\hline S1 & 42 & $42 \%$ \\
\hline Lain nya & 15 & $15 \%$ \\
\hline Jumlah & 100 & $100 \%$ \\
\hline
\end{tabular}

Sumber : Data Primer yang Diolah, 2020

Dari data 3 diatas menunjukkan bahwa responden dengan pendidikan $\mathrm{S} 1$ paling dominan dengan jumlah 42 orang atau $42 \%$. Untuk lulusan SMA sebanyak 25 orang atau 25\% dan lulusan SMP sebanyak 18 orang atau $18 \%$, sedangkan sisanya sebanyak 15 orang atau $15 \%$ berasal dari pendidikan lain nya

\section{Responden menurut pekerjaan}

Data Karakteristik responden berdasarkan pekerjaan dapat dilihat pada tabel berikut :

Tabel 4

\section{Responden menurut pekerjaan}

\begin{tabular}{|c|c|c|}
\hline Keterangan & Frekuensi & Presentase \\
\hline Wiraswasta & 25 & $25 \%$ \\
\hline Karyawan & 35 & $35 \%$ \\
\hline PNS & 28 & $28 \%$ \\
\hline Lain nya & 12 & $12 \%$ \\
\hline Jumlah & 100 & $100 \%$ \\
\hline
\end{tabular}

Dari tabel 4 diatas menunjukkan bahwa responden paling dominan adalah karyawan sebanyak 35 orang atau $35 \%$, untuk wiraswasta sebanyak 25 orang atau $25 \%$ dan PNS sebanyak 28 orang atau $28 \%$ sedangkan sisanya sebanyak 12 orang atau $12 \%$ berasalan dari pekerjaan lain nya.

\section{Uji Validitas}

Uji validitas digunakan untuk mengukur sah atau valid tidaknya suatu kuesioner. Suatu kuesioner dikatakan valid jika pertanyaan pada kuesioner mampu mengungkapkan sesuatu yang akan diukur oleh kuesioner tersebut. Pengukuran validitas dalam penelitian ini menunjukkan jumlah varians dari indikator yang di ekstrasi oleh konstruk/variabel laten yang dikembangkan. Nilai variance variance extract yang dapat diterima adalah minimal 0,50 .

Tabel 5

Hasil Uji Validitas

\begin{tabular}{|l|c|}
\hline \multicolumn{1}{|c|}{ Variabel } & $\begin{array}{c}\text { Variance } \\
\text { Extract }\end{array}$ \\
\hline $\begin{array}{l}\text { Experiential } \\
\text { marketing }\end{array}$ & 0,558 \\
\hline Kualitas Pelayanan & 0,589 \\
\hline Kepuasan Nasabah & 0,535 \\
\hline Kualitas Pelayanan & 0,686 \\
\hline
\end{tabular}

Sumber : Data primer yang diolah, 2020

Dari tabel 5 diatas menunjukkan bahwa hasil uji validitas dengan menggunakan nilai variance Extract yang disajikan dalam tabel diatas menunjukkan nilai variance extract untuk masing-masing variabel telah memenuhi kriteria yang disyaratkan.

\section{Uji Reliabilitas}

Uji reliabilitas merupakan uji kehandalan yang bertujuan untuk mengetahui seberapa jauh suatu alat ukur dapat diandalkan atau dipercaya. Uji reliabilitas menunjukkan sejauh mana suatu alat ukur

\section{Arif Afendi}

Strategi Experiential Marketing Dan Kualitas Pelayanan Dalam Menjelaskan Kepuasan Dan Loyalitas Nasabah Pada Bank Syariah Mandiri Semarang 


\section{SEGMEN Jurnal Manajemen dan Bisnis \\ Volume 17 No 1 Januari 2021 \\ p-ISSN: 0216-938X e-ISSN: 2684-8414}

dapat memberikan hasil yang relative sama apabila dilakukan pengukuran kembali pada obyek yang sama. Uji reliabilitas dalam penelitian ini dilakukan dengan menggunakan nilai Reliability Construct. Nilai reliabilitas minimum dari dimensi/indicator pembentuk variabel laten yang dapat diterima adalah sebesar 0.70 .

Dari tabel 6 diatas menunjukkan bahwa hasil uji reliabilitas yang disajikan dalam Tabel diatas menunjukkan bahwa nilai Reliability Construct untuk masing-masing variabel laten $>0.7$ sehingga dapat disimpulkan bahwa alat ukur masing-masing variabel laten dapat diandalkan atau dipercaya.

Tabel 7

Uji hipotesis

Hasil Uji Reliabilitas
\begin{tabular}{|c|c|}
\hline Variabel & Reliability \\
\hline $\begin{array}{c}\text { Experiential } \\
\text { marketing }\end{array}$ & 0,834 \\
\hline Kualitas Pelayanan & 0,851 \\
\hline Kepuasan Nasabah & 0,806 \\
\hline Kualitas Pelayanan & 0,861 \\
\hline
\end{tabular} Sumber: Data primer yang diolah, 2020

\section{PENGUJIAN HIPOTESIS DAN PEMBAHASAN}

Uji hipotesis dilakukan untuk mengetahui berpengaruh atau tidakanya variabel independent terhadap variabel dependen.

\begin{tabular}{|c|c|c|c|c|c|}
\hline \multicolumn{6}{|c|}{$\begin{array}{c}\text { Tabel } 7 \\
\text { Uji hipotesis }\end{array}$} \\
\hline & & Estimate & S.E. & C.R. & $\mathbf{P}$ \\
\hline Kepuasan Nasabah $\leftarrow$ & Experiential marketing & 0,229 & 0,109 & 2,093 & 0,036 \\
\hline Kepuasan Nasabah $\leftarrow$ & Kualitas Pelayanan & 0,262 & 0,113 & 2,321 & 0,020 \\
\hline Loyalitas_Nasabah $\leftarrow$ & Kepuasan Nasabah & 0,503 & 0,157 & 3,203 & 0,001 \\
\hline Loyalitas_Nasabah $\leftarrow$ & Kualitas Pelayanan & 0,069 & 0,033 & 2,109 & 0,035 \\
\hline Loyalitas Nasabah $\leftarrow$ & Experiential marketing & 0,035 & 0,025 & 1,411 & 0,158 \\
\hline
\end{tabular}

Sumber : Data primer yang diolah, 2020

\section{Pengaruh Experiential marketing Terhadap Kepuasan Nasabah}

Parameter estimasi untuk pengujian pengaruh Experiential marketing terhadap Kepuasan Nasabah menunjukkan nilai CR sebesar 2,093 dengan probabilitas sebesar 0,036 . Oleh karena nilai probabilitas $<0,05$ maka dapat disimpulkan bahwa Experiential marketing berpengaruh positif dan signifikan terhadap Kepuasan Nasabah. Dengan demikian hipotesis 1 Diterima. Hasil penelitian ini sesuai dengan hasil penelitian yang dilakukan oleh Yuan \& Wu (2008), Lee, Hsiao \& Yang (2010) dan Rosanti, Srikandi \& Yuliyanto (2013) yang mengatakan bahwa experiential marketing memiliki pengaruh

Arif Afendi

Strategi Experiential Marketing Dan Kualitas Pelayanan Dalam Menjelaskan Kepuasan Dan Loyalitas Nasabah Pada Bank Syariah Mandiri Semarang 


\section{SEGMEN Jurnal Manajemen dan Bisnis \\ Volume 17 No 1 Januari 2021 \\ p-ISSN: 0216-938X e-ISSN: 2684-8414}

yang positif terhadap kepuasan pelanggan. Experiential marketing adalah proses untuk mengidentifikasi dan memuaskan kebutuhan dan aspirasi nasabah, menyatukannya melalui komunikasi dua arah yang membawa merek ke dalam kehidupan dan membawa nilai ke nasabah yang dituju. Experiential Marketing berperan penting dalam menciptakan kepuasan pada nasabah. Adanya kepuasan pada nasabah ini dapat disebabkan oleh konsep tempat yang disediakan oleh bank syariah mandiri. Selain itu pengalaman positif yang diterima nasabah saat berkunjung dan menabung akan menimbulkan rasa puas dalam benak nasabah. Jadi, dapat disimpulkan bahwa Experiential Marketing merupakan salah satu cara untuk membangun dan meningkatkan kepuasan nasabah. Hasil penelitian ini sesuai dengan teori yang dikemukakan oleh Garbarino \& Johnson (2001), kepuasan secara keseluruhan berdasarkan pada penggunaan dan pengalaman menggunakan produk dan jasa. Pengalaman yang baik dan mengesankan akan menciptakan timbulnya perasaan positif atau perasaan puas dan emosi terhadap merek. Jadi kepuasan pelanggan dapat terbentuk apabila pelanggan merasakan kenyamanan dalam hubungannya dengan perusahaan dan apa yang dia dapatkan sama dengan harapan yang diinginkan. Andreani (2007), menyatakan dengan adanya experiential marketing pelanggan akan mampu membedakan produk dan jasa yang satu dengan lainnya karena mereka dapat merasakan dan memperoleh pengalaman secara langsung. Jadi kesimpulannya Experiential marketing yang dilakukan oleh bank syariah mandiri semarang bisa mendorong kepuasan pelanggan melalui nilai-nilai emosional dan fungsional artinya semakin baik pengalaman yang didapat oleh pelanggan maka kepuasan yang dirasakan akan semakin meningkat.

\section{Pengaruh Kualitas Pelayanan Terhadap Kepuasan Nasabah}

Parameter estimasi untuk pengujian pengaruh Kualitas Pelayanan terhadap Kepuasan Nasabah menunjukkan nilai CR sebesar 2,321 dengan probabilitas sebesar 0,020 . Oleh karena nilai probabilitas $<0,05$ maka dapat disimpulkan bahwa Kualitas Pelayanan berpengaruh positif dan signifikan terhadap Kepuasan Nasabah. Dengan demikian hipotesis 2 Diterima. Hasil penelitian ini sesuai dengan hasil penelitian yang dilakukan oleh Sureshchandar, Chandrasekharan \& Anantharaman (2002) dan Aryani \& Febriana (2010) menyatakan bahwa kualitas pelayanan memiliki pengaruh yang positif terhadap kepuasan pelanggan. Kualitas pelayanan yang baik di dalam suatu perusahaan, akan menciptakan kepuasan bagi para pelangganya. Setelah pelanggan merasa puas dengan produk atau jasa yang diterimanya, pelanggan akan membandingkan pelayanan yang diberikan. Apabila pelanggan merasa benar-benar puas, mereka akan membeli ulang serta memberi rekomendasi kepada orang lain untuk membeli di tempat yang sama. Artinya semakin baik tingkat kualitas pelayanan yang diberikan kepada pelanggan maka tingkat kepuasaan akan semakin tinggi.

\section{Pengaruh Kepuasan Nasabah Terhadap Loyalitas Nasabah}

Strategi Experiential Marketing Dan Kualitas Pelayanan Dalam Menjelaskan Kepuasan Dan Loyalitas Nasabah Pada Bank Syariah Mandiri Semarang 


\section{SEGMEN Jurnal Manajemen dan Bisnis \\ Volume 17 No 1 Januari 2021 \\ p-ISSN: 0216-938X e-ISSN: 2684-8414}

Parameter estimasi untuk pengujian pengaruh Kepuasan Nasabah terhadap Loyalitas Nasabah menunjukkan nilai CR sebesar 3,203 dengan probabilitas sebesar 0,001 . Oleh karena nilai probabilitas $<0,05$ maka dapat disimpulkan bahwa Kepuasan Nasabah berpengaruh positif dan signifikan terhadap Loyalitas Nasabah. Dengan demikian hipotesis 3 Diterima. Hasil penelitian ini sesuai dengan hasil penelitian yang dilakukan oleh Lee, Hsiao \& Yang (2010) mengatakan bahwa kepuasan pelanggan memiliki pengaruh yang positif terhadap loyalitas pelanggan artinya ketika seseorang pelanggan merasa senang dan puas terhadap produk serta pelayanan yang diberikan maka akan membuat mereka semakin loyal dan setia terhadap produk tersebut serta akan semakin susah untuk pindah dengan menggunakan produk lain yang sejenis. Ini seperti teori yang dikemukakan oleh kotler (2005) bahwa kepuasan adalah hasil yang dirasakan oleh pembeli yang mengalami kinerja sebuah perusahaan yang sesuai dengan harapannya. Pelanggan merasa puas jika harapan mereka terpenuhi, dan merasa sangat senang kalau harapannya terlampaui. Adanya kepuasan yang sesuai dengan harapan pelanggan menginginkan kembali untuk kepuasan secara berulang-ulang dan hal inilah yang akhirnya meningkatkan loyalitas pelanggan.

\section{Pengaruh Kualitas Pelayanan Terhadap Loyalitas Nasabah}

Parameter estimasi untuk pengujian pengaruh Kualitas Pelayanan terhadap Loyalitas Nasabah menunjukkan nilai CR sebesar 2,109 dengan probabilitas sebesar 0,035 . Oleh karena nilai probabilitas $<0,05$ maka dapat disimpulkan bahwa Kualitas Pelayanan berpengaruh positif dan signifikan terhadap Loyalitas Nasabah. Dengan demikian hipotesis 4 Diterima. Hasil penelitian ini sesuai dengan hasil penelitian yang dilakukan oleh Starini (2013) menyatakan bahwa kualitas pelayanan berpengaruh secara positif terhadap loyalitas pelanggan. Kualitas pelayanan merupakan faktor utama yang mempengaruhi loyalitas pelanggan dikarenakan pelanggan yang terpuaskan nilai pribadinya dan mengalami suasana hati yang positif terhadap pelayanan akan memiliki loyalitas yang tinggi terhadap perusahaan tersebut. Pelanggan seringkali tidak loyal disebabkan oleh adanya pelayanan yang buruk atau kualitas pelayanan yang semakin menurun dari yang diharapkan pelanggan.

\section{Pengaruh Experiential marketing Terhadap Loyalitas Nasabah}

Parameter estimasi untuk pengujian pengaruh experiential marketing terhadap Loyalitas Nasabah menunjukkan nilai CR sebesar 1,411 dengan probabilitas sebesar 0,158 . Oleh karena nilai probabilitas $>0,05$ maka dapat disimpulkan bahwa experiential marketing berpengaruh positif namun tidak signifikan terhadap loyalitas Nasabah. Dengan demikian hipotesis 5 Diterima. Hasil penelitian ini sesuai dengan hasil penelitian yang dilakukan oleh Obonyo (2011) mengatakan bahwa experiential marketing memiliki pengaruh yang positif terhadap loyalitas pelanggan. Experiential marketing bisa mendorong kepuasan pelanggan melalui nilai-nilai emosional dan fungsional sehingga mengakibatkan pelanggan akan menjadi loyal artinya semakin baik pengalaman yang 


\section{SEGMEN Jurnal Manajemen dan Bisnis \\ Volume 17 No 1 Januari 2021 \\ p-ISSN: 0216-938X e-ISSN: 2684-8414}

didapat oleh pelanggan maka kepuasan yang dirasakan akan semakin meningkat sehingga pelanggan akan menjadi semakin loyal terhadap perusahaan.

\section{KESIMPULAN}

Berdasarkan hasil Analisis Pengaruh strategi experiential marketing dan kualitas pelayanan terhadap kepuasan dan loyalitas nasabah maka bisa diambil kesimpulan bahwa pengaruh experiential marketing terhadap kepuasan nasabah adalah positif dan signifikan artinya experiential marketing yang dilakukan oleh bank syariah mandiri semarang bisa mendorong kepuasan pelanggan melalui nilai-nilai emosional dan fungsional artinya semakin baik pengalaman yang didapat oleh pelanggan maka kepuasan yang dirasakan akan semakin meningkat. Pengaruh kualitas pelayaan terhadap kepuasan nasabah adalah positif dan signifikan artinya semakin baik tingkat kualitas pelayanan yang diberikan kepada pelanggan maka tingkat kepuasaan akan semakin tinggi. Pengaruh kepuasan nasabah terhadap loyalitas nasabah adalah positif dan signifikan artinya semakin tinggi tingkat kepuasan nasabah yang diperoleh maka akan menyebabkan seorang nasabah semakin loyal. Pengaruh kualitas pelayanan terhadap loyalitas nasabah adalah positif dan signifikan artinya semakin bagus kualitas pelayan yang diberikan maka membuat seorang nasabah semakin loyal dan Pengaruh experiential marketing terhadap loyalitas nasabah adalah positif namun tidak signifikan artinya experiential marketing bisa mendorong kepuasan pelanggan melalui nilai-nilai emosional dan fungsional sehingga mengakibatkan pelanggan akan menjadi loyal artinya semakin baik pengalaman yang didapat oleh pelanggan maka kepuasan yang dirasakan akan semakin meningkat sehingga pelanggan akan menjadi semakin loyal terhadap perusahaan.

\section{SARAN}

Beberapa saran yang dapat peneliti sampaikan berdasarkan analisis yang telah dilakukan adalah Untuk bank syariah mandiri agar terus menciptakan pengalaman positif bagi nasabah serta meningkatkan kinerja karyawan agar mereka merasa puas dan membuat nasabah semakin loyal. Penelitian selanjutnya sebaiknya mencoba menguji dengan menambahkan jumlah sampel penelitian. Bagi penelitian selanjutnya diharapkan dapat melakukan penelitian sejenis dengan penambahan variabel dan objek penelitian yang berbeda selain perbankan agar dapat mengetahui pengaruh dari setiap variabel

\section{DAFTAR PUSTAKA :}

Andreani, F. (2007). Experiential Marketing : Sebuah Pendekatan Pemasaran. Jurnal Manajemen Pemasaran. Manajemen Pemasaran. Erlangga. Jakarta.

Aryani, Dwi dan R.Febriana. (2010). Pengaruh Kualitas Layanan terhadap Kepuasan Pelanggan dalam membentuk Loyalitas Pelanggan. Jurnal Administrasi dan Organisasi. Vol.17.2, h.114-126.

Christian dan Dharmayanti, 2013. Pengaruh Experiential Marketing terhadap Customer Satisfaction dan Customer Loyality the Light Cup di Surabaya Town 


\section{SEGMEN Jurnal Manajemen dan Bisnis \\ Volume 17 No 1 Januari 2021 \\ p-ISSN: 0216-938X e-ISSN: 2684-8414}

Square. Jurnal Manajemen Pemasaran Petra, Vol 1 No 2.

Garbarino, Ellna and mark S. Johnson, 2001. The Different Role Of Satisfiction, Trust And Commitment In Consumer Relationships. Jurnal of Marketing, Vol 63, April, p. 7087

Griffin, Jill. (2005). Customer Loyalty (edisi revisi dan terbaru). Jakarta: Erlangga.

Kotler \& Amstrong. 2012. Prinsip-prinsip Pemasaran. Jilid 1. Edisi Kedelapan. Jakarta: Erlangga

Kotler, Philip (2005), Manajemen Pemasaran, PT. Prenhallindo, Jakarta.

Lee, Ming-Shing, Huey-Der Hsio dan MingFen Yang, 2010. The Study of The Relationships among Experiential Marketing, Service Quality, Customer Satisfaction and Customer Loyalty. International Journal of Organizational Innovation.

Obonyo, Moses. (2011). Experintial Marketing, Experiential Value, PurchaseBehavior, and Loyalitas in The Telecoms Industry. Research Dissertationfor The Award of Master of Science in Marketing. Uganda: MakerereUniversity.

Parasuraman et al., (1985). A conceptual model of service quality and its implications for future researh. Journal of marketing. Vol. 49

Putri, Yuwandha \& Astuti, Sri Rahayu. 2010. Analisis Pengaruh Experiential Marketing terhadap Loyalitas Pelanggan Hotel X Semarang. Aset, 12(2): 191199.
Rosanti,N, Srikandi,K dan Edy Yulianto, 2014. Pengaruh Experiential Marketing dan Experiential Value terhadap Customer Satisfaction: Survei pada Mahasiswa FIA Bisnis 2013/2014 Pengguna Android Samsung”, Jurnal Administrasi Bisnis, Vol.16, No.1 November

Schmitt, Bernd H. 1999. Experiential Marketing: How to Get Customers to Sense, Feel, Think, Act, and Relate to Your Company and Brands. New York: The Free Press.

Starini, Hygid. (2013). Pengaruh Kualitas Pelayanan terhadap Loyalitas Konsumendengan Kepuasan sebagai Variabel Mediasi (Studi Pada Toko Basuki JayaYogyakarta). Skripsi Tidak Diterbitkan. Universitas Negeri Yogyakarta.

Sureshchandar, G. S., Chandrasekharan Rajendran, dan R. N. Anantharaman. 2002. The Relationship Between Service Quality and Customer Satisfaction: A Factor Specific Approach. Journal of Services Marketing, 16 (4): 363-379.

Tjiptono, Fandy. 2006. Pemasaran Jasa. Malang : Bayumedia

Wijayanti, Ari. (2008). Strategi Meningkatkan Loyalitas melalui Kepuasan Pelanggan. Research Dissertation for The Award of Magister Management. Semarang: Universitas Diponegoro.

Yi-Hua Erin Yuan dan Chihkang Kenny Wu, 2008. Relationships among Experiential Marketing, Experiential Value, and

\section{Arif Afendi}

Strategi Experiential Marketing Dan Kualitas Pelayanan Dalam Menjelaskan Kepuasan Dan Loyalitas Nasabah Pada Bank Syariah Mandiri Semarang 


\section{SEGMEN Jurnal Manajemen dan Bisnis \\ Volume 17 No 1 Januari 2021 \\ p-ISSN: 0216-938X e-ISSN: 2684-8414}

Customer Satisfaction. Journal of

Hospitality \& Tourism Research

Zeitahml, VA. 1998. Consumer Perception of Price, Quality and Service, A Means Model and Syntesis of Exidence. Journal of Marketing. Vol 52. July. P. 2-22.

Zeithmal, A. Z., Leonard, L. B., \& Parasuraman, 2006. The Behavioral Consequences of Service Quality. Journal of Marketing. 60. 31-46. 